\title{
Network Development under the Condition of Network Supervision and Network Ethics
}

\author{
Deng Tian \\ NanChang Institute of Science \& Technology
}

Keywords: Ecological balance; Network supervision; Network ethics

\begin{abstract}
With the rapid development of Internet, it also brings a lot of ethical and social problems. If we do not regulate the development of the network and ethics, it is bound to affect the healthy and orderly development of the network. Through the analysis of the influence of network ethics on the development of the future network, this paper discusses the network development under the condition of network supervision and network ethics. The Internet has shortened the distance between people and regions, and it has become more and more closely related to people, and has become an indispensable part of people's work, life and study. However, most people's understanding of the network is still limited to the technical level. From a technical point of view, people think more of the network as a tool. Based on the basic principles of ecology, this paper considers the network as an ecosystem, and discusses how to maintain the balance of the network ecosystem. The network will also appear system disorders, the emergence of "network environment" crisis. This study starts from the understanding of computer network, understand the development process of the network, and so on with the rapid development of the network society, government, academic circles pay more attention to the network, the research on network analysis is increasingly perfect, and the concept of network ecosystem is gradually formed.
\end{abstract}

\section{Introduction}

In the current network security management work, the most popular management method used by relevant technical staffs is the "development and operation of the network monitoring software, but due to the current state of the network monitoring software management lacks a certain standard, so very easily lead to network software using the "supervision" in the name. Protect user computer system security at the same time, the invasion of privacy and disclosure. Therefore, with the continuous development of network technology, more and more close to people's lives, and provide a service for people, more attention should be paid to the safety supervision and safety control on the related technology, network technology and Society for others to prevent a huge effect on the role of people's life and work.

In the past, it was once believed that the emergence of computer and network technology is the crystallization of human wisdom, and the control of the crystallization of the control in their own hands. But later, people suddenly found the original control in their own hands the right to have quietly been taken, the user not only to lose control of the computer and network technology, and even its own privacy right and right and other related rights also suffered infringement of computer and network technology. To re-examine and positioning of the network technology and the emergence of this phenomenon had to let us, issues related to computer and network technology, the use of security and network supervision as well as the significance of network ethics value, we need to know.

\section{Embodiment of Security Value in Computer Network}

Nowadays, with the acceleration of the process of social information, the development of the network has more and more extensive research. Is a top priority. Different from the traditional legal norms of real people's external behavior, network law is still not perfect, need to further strengthen the management, on the basis of this, some scholars basic concept of network law is summarized as "the maintenance of order, the protection of the rights and freedom of sharing". That is to say, under 
the network environment, the basic value of human beings still plays an important role. At the same time, the author thinks that on the basis of the above three basic concepts, there should be a higher level of security. Security in Baidu encyclopedia explanation is not threatened, no danger, harm, loss. Refers to the natural environment of human harmony and interdependence. No harm does not exist related hazards. The state of being exempted from unacceptable risk of injury. That is to say, safety should be able to avoid the danger that is happening and the risk and loss. Security is a relative concept, and the general understanding of the macro is safe.

Thus, it can be understood that the concept of security must run through the entire process of surfing the Internet and seek a balance between the reality and virtual life. Therefore, we need to build a world that is full of order, protection of rights, and freedom to share. The primary factor should also be to make the world a safer and more secure world.

\section{Network Development under the Condition of Network Supervision and Network Ethics}

In the era of rapid development of network, network supervision is important, but the network supervision is often a delay, but the data on the network is massive, impossible to monitor the network information content will be able for the first time, and often when the regulatory force, the network may have improper content in a certain range and even in the whole country the world has a great influence. For example, the salt rush events, all kinds of rumors spread quickly. In this case, the network ethics is particularly important. The so-called network ethics, refers to the people through the electronic information network to show the social relations of moral relations". These moral relations restrict the behavior of participants in the process of network information transmission, which is the moral standards and norms that people should abide by in cyberspace. However, the particularity of the Internet makes it very different from the original social ethics. At present, in the development of the Internet, has not yet formed a mature new moral standard, which led to the status of the network space ethics confusion, mainly reflected in the following aspects:

Serious Information Pollution. With the prosperity of network information, there are a large number of pornography, violence and false information on the Internet. These have a negative impact on the ethics of the real society, especially for the growth of young people.

Information Security Crisis. There are computer viruses, hackers, Internet fraud, infringement of personal privacy and other acts of infringement.

\section{Measures to Maintain Ecological Balance of the Network}

The network is the ecosystem of people and information. Therefore, this kind of contradiction is not a crisis of individual elements, but a crisis of network ecology. To solve this kind of problem is undoubtedly a systematic project, which requires not only the efforts of the government, enterprises and individuals, but also the need to strengthen international cooperation. It is necessary to attach importance to the role of network technology, but we also cannot ignore the significance of law and ethics. Better network is the common aspiration of mankind. To this end, we not only need to rely on technological progress, but also need to strengthen the network ethics, legal research and construction. Only by working together with ethics and law can technology create a more humane network, an ecological network.

Improve Network Technology. At present, a wide range of network security precautions and cross each other. Microsoft and other European and American companies have jointly developed PICS (Platform for Internet Content Selection), namely "choice platform monitoring software of Internet content, to limit the access to network information, and to monitor the specific information, its purpose is" efforts will not be good information, poor information, repetitive information pollution information or, at least to some limit out of Internet communication". The development of new technologies to ensure information security network information security technology, including data encryption technology, firewall technology, access control technology, anti-virus technology, etc. 
Strengthen Network Supervision. Although the technical guard is a common method to guarantee the network security, no matter what encryption or higher security technology the information network adopts, with the development of science and technology, it only increases difficulty to those cyber-crime criminals, but cannot solve the problem fundamentally. Therefore, in order to solve the problem of network ecological crisis and regulate the network behavior, in addition to strengthening the technical prevention, it is necessary to develop a relevant network behavior department law, strengthen law enforcement efforts to strengthen the management of the internet.

Establish the Network Ethics Consciousness. The network is the second living space of human, ecological and information, which requires the network to keep a dynamic balance in the overall significance, structural, to maintain this balance, in addition to the technology and law, network ecology ethics is necessary. Strengthen the network ethics consciousness, with the popularization of the network, network ethics, network law and regulation consciousness is constantly strengthening. If people can be self-disciplined, consciously assume their own ethical responsibility, the problem will ease a lot.

\section{Conclusion}

With the introduction of the new $4 \mathrm{G}$ technology, the computer network will be everywhere. A healthy green network environment, the need for strict network regulation, everyone follow the network ethics, such a network is what we are looking for, but also the future development of the network must first do a good job. If we develop blindly and only pursue economic benefits and advanced science and technology, the contribution of its development cannot make up for the harm. Only under the conditions of network supervision and network ethics, network development is the demand of the society. In order to solve the problems brought by the development of computer network, on the one hand, in addition to the government and the corresponding operator service providers to do the network supervision, on the other hand, as the network users, each participating individual, should comply with the network ethics, and make joint efforts to create a clean and harmonious network.

Project funding. Nanchang Intelligent Building Network Engineering Key Laboratory \& Specialty of Jiangxi Province (NGTSZY201001)

\section{References}

[1] Barnett J E, Molzon C H. Clinical Supervision of Psychotherapy: Essential Ethics Issues for Supervisors and Supervisees [J]. Journal of Clinical Psychology, 2014, 70(11):1051 - 1061.

[2] Lian X J. On the Basics of the Construction of Network Ethics [J]. Journal of Shenyang Normal University Social Sciences Edition, 2004.

[3] Xiao-Yu L I. On Discussion of "Virtual Community" Ethics Building --"Self-supervision"[J]. Journal of North China Institute of Water Conservancy \& Hydroelectric Power, 2013.

[4] Xu X B. Research on the Actual Combat-Oriented Mode of Network Security Supervision Based on Networked Resources [J]. Advanced Materials Research, 2013, 791-793:1710-1715.

[5] Esler M T. 'What Should I do?' a study of social work ethics, supervision and the ethical development of social workers[J]. Australian Catholic University School of Social Work, 2007.

[6] Cheng J H. Improving Ethical and Moral Education of the Network [J]. Journal of Qiqihar University, 2010.

[7] Liu C. Talk about the Puzzled and Construction of the Ethics of the Network [J]. Researches in Library Science, 2005. 
[8] Han G B, Zhang L N. Research on Construction Engineering Quality Supervision Based on Artificial Neural Network [J]. Advanced Materials Research, 2014, 919-921:1471-1476.

[9] Paula É S D, Nascimento L C, Rocha S M M. La influencia del apoyo social para el fortalecimiento de las familias de niños con insuficiencia renal crónica [J]. Rev. Latino-Am. Enfermagem, 2008, 16.

[10]Buckley C L, Tajima S, Yanagawa T, et al. Brain State Control by Closed-Loop Environmental Feedback [J]. 2016.

[11]Liang J X, Cai Y T. Design and Application of Network Management System for Sports Events [J]. Applied Mechanics \& Materials, 2012, 263-266:3357-3360.

[12] Organization W H. WHO drug information [J]. Who Drug Information, 1987, 3(4):13-18. 